\title{
Agent Focus in Yukatek and Lakandon Maya
}

\author{
HENRIK BERGQVIST \\ Endangered Languages Academic Programme, SOAS, University of London.
}

\section{Introduction}

This paper discusses agent focus (AF) constructions in Yukatek and Lakandon Maya. ${ }^{1} \mathrm{AF}$ as a distinct grammatical construct has been noted and investigated for languages all over the world, and analyzed in different ways depending on the language specific circumstances.

Aissen (1999) mentions Dyirbal (Dixon 1972) as an example of a language where AF is a form of anti-passive construction that requires the object to be demoted to an oblique constituent. Several Mayan languages, on the other hand, have a specific morphological AF-marker that basically marks a transitive verb phrase as intransitive while still retaining a transitive function, a construction that is discussed below (cf. Aissen 1999).

In Yukatek and Lakandon Maya, AF constructions require changes in status marking on the verb that in part, are syntactically motivated. Status markers signal valence and determine aspect-mood (AM) inflection, but although the observed changes are required syntactically, they are also dependent on semantic features connected to the roles of agent-patient.

Lucy (1994) argues that the interaction between verb roots and status marking in Yukatek reveals argument structure as a feature of both categories. Lucy's proposal is applied to AF constructions in Yukatek and Lakandon Maya in order to explain the grammatical properties of the construction and the observed changes in status marking.

The suggestion here is that relative agent salience determines the use of status markers in AF constructions and that a hierarchy along those lines is proposed to

\footnotetext{
${ }^{1}$ Yukatek and Lakandon Maya are both languages belonging to the Yukatekan branch of the Mayan language family. The Lakandon Maya data presented in this paper was collected by the author in the field between 2003-2006; first under the auspices of the Project for the Documentation of the Languages of Meso-America (PDLMA, http://www.albany.edu/pdlma), and later as a documentation of Lakandon Maya funded by the Endangered Languages Documentation Programme (ELDP, http://www.hrelp.org), grant IGS0038. I wish to extend my gratitude to both organisations for supporting my research.
} 


\section{Henrik Bergqvist}

explain the changes in status marking as they can be observed in both Yukatek and Lakandon Maya.

\section{Agent Focus in Mayan Languages}

Agent extraction is a grammatical operation that is used to grammatically highlight the agent in a transitive clause. As indicated above, such an operation can be analysed in various ways depending on the strategies used in individual languages.

Verb-initial ergative languages (e.g. Mayan languages) often show morphosyntactic consequences from the extraction of the agent, which are not present in subject- or object extraction.

In many Mayan languages, the extraction of an agent requires an AF construction that is morphologically intransitive, but semantically and functionally transitive. AF constructions are present in Mayan languages from different branches of the Mayan family tree: e.g. Ixil (Mamean), Jakaltek (Q'anjob'alan), K'iche' (K'ichean), Tzotzil (Tzeltalan), and Tz'utujil (K'ichean). These languages all make use of either of two available reflexes of the reconstructed proto-Mayan suffixes *-on and *-wa (Aissen 1999; Yasugi 2005).

An example of a construction from Tz'utujil is seen in (1), below:

$$
\begin{aligned}
& \text { Naq } \quad x-\varnothing-(X-) \text { sok-ow-i? }{ }^{2} \\
& \text { who COM-3SG.B-hurt-AF-TERM } \\
& \text { 'Who hurt him?' (Dayley 1985:352) }
\end{aligned}
$$

In (1), the agent has been removed from the verb compound and is represented by the free-standing indefinite pronoun naq ('who'). Accompanying this extraction is the AF-marker -ow.

A possibly special case in the Mayan context is discussed by Aissen (1999) who argues that AF verbs in Tzotzil are inverse as part of a system of obviation (cf. Aissen 1997).

Obviation is the hierarchical marking of third person subjects and objects as proximate or obviate so as to function as a referential tracking device for nominals. In obviation systems there is an established hierarchy following parameters like human/non-human, definite/indefinite and individuated/non-individuated, where human, definite, and individuated are proximate, and the opposite features are obviate.

Aissen argues for the presence of such a system in agent focus constructions in Tzotzil since they are only used when the agent is lower on the proximate/obviate hierarchy. AF verbs are furthermore only possible to use if the agent and the patient both are marked in third person. This restriction is not found

\footnotetext{
${ }^{2}(\mathrm{X}-)$ marks the extracted agreement marker while - $(-)$ marks an invisible, but present agreement marker.
} 
in Tz'utujil, for example, where first person agents and patients are allowed in agent focus constructions (Aissen 1999:452).

An example of an AF verb in Tzotzil is seen in (2). The agent focus marker in Tzotzil is a reflex of the proto-Mayan suffix *-on.

$$
\begin{aligned}
& \text { B'uch'u i-Ø-(X-)kolta-on li tzeb-e? } \\
& \text { who COM-3SG.B-help-AF the girl-ENC } \\
& \text { 'Who helped the girl?' (Aissen 1999:453) }
\end{aligned}
$$

In preparation for the analysis of AF constructions in Lakandon in the remainder of the paper, it may be noted that Tzotzil has no apparent restrictions regarding AM-marking on AF verbs. All available tense, aspect, and mood markers appear to be available for AF verbs in Tzotzil. As stated, AF verbs are also morphologically intransitive, a situation that is not paralleled in Yukatek and Lakandon Maya.

\section{Verbal Case Marking in Yukatek and Lakandon}

Yukatekan and Cholan languages have a typologically rare intransitive split system (split-S) that is governed by aspect ${ }^{3}$ (cf. Bohnemeyer 2004). Intransitive verbs in the plain status, mark the subject with the ergative marker (setA). Intransitive verbs in the completive and dependent statuses mark the subject with the absolutive marker (setB).

Since the split only concerns intransitive subjects, transitive verbs have an ergative-absolutive marking of agent and object, respectively, regardless of status. Below, (3-6) are examples from Lakandon Maya illustrating this: ${ }^{4}$

$$
\begin{aligned}
& \text { Root transitive: Incompletive } \\
& k \text {-in-jätz'-ik- } \boldsymbol{\emptyset} \\
& \text { INC-1SG.A-hit-PLN.TR-3SG.B }{ }^{5} \\
& \text { 'I am hitting him' }
\end{aligned}
$$

\footnotetext{
${ }^{3}$ Aspect in this sense is inseparable from the notion of status (cf. Kaufman 1990) which primarily indicates the valence of a verb, but which also interacts with aspect-mood as well as person inflection.

${ }^{4}$ The orthographic conventions used in this paper follow the Official Mayan Orthography with two notable exceptions: $/ \mathrm{h} /$ marks high tone and $/ 7 /$ the glottal stop.

5 Abbreviations used in glossing: 1: first person, 2: second person, 3: third person, A: ergative marker, AF: agent focus, B: absolutive marker, CAUS: causative, COM: completive aspect, CP: completive status, DEP: dependent status, DET: determiner, DUB: dubitative, ENC: enclitic, EXCL: exclusive, EXIST: existential, FUT: future, IMP: imperative, INC: incompletive aspect, IND: independent form, IV: intransitive, NEG: negative, OST: ostensive form, SG: singular, PL: plural, PLN: plain status, TERM: phrase final, TR: transitive, TRZ: transitivizer suffix
} 
(4) Root transitive. Completive

t-in-jätz'-aj-Ø

COM-1SG.A-hit-CP.TR-3SG.B

'I hit him'

(5) Root intransitive: Incompletive

$k$-inw-ehm-an

INC-1SG.A-go.down-PLN.IV

'I am going down'/ 'I am descending'

(6) Root intransitive: Completive

7ehm-Ø-een

go.down-CP.IV-1SG.B

'I went down'/ 'I descended'

The marking of aspect and status also depends on the semantic and formal classification of the verb root. This is discussed in section 4. First we turn to look at the somewhat special case of AF in Yukatek and Lakandon Maya.

\section{AF and Agent Extraction in Yukatek and Lakandon Maya}

In Yukatek Maya, the grammatical operation of agent extraction has been called ergative extraction (Kaufman 1991) and described as a process that may apply as a result of a focus construction highlighting the agent in a clause (ibid:173).

AF constructions in Yukatek and Lakandon Maya are different from the ones Aissen presents for Tzotzil in several respects. Some of these differences are discussed here as a comparison between two distinct strategies.

In Yukatek and Lakandon Maya, the ergative person marker (setA) is extracted from the verb compound, leaving the transitive verb phrase partially marked as intransitive although it still has a transitive function. The person (cross reference) marker is removed from the inflected verb to occupy a preverbal position. This situation is no different from e.g. AF verbs in Tzotzil, but in contrast, the extracted verb in Yukatek and Lakandon Maya morphologically retains transitive status marking. However, a change in status marking also occurs where only the plain and dependent status markers are available in AF constructions.

There is also a restriction on available AM-markers where only three AMcategories are permitted, i.e. the incompletive/habitual, (indefinite) future, and the completive. Yukatek and Lakandon Maya allow the full range of persons in an agent focus construction, making the inverse analysis found in Tzotzil nonapplicable to AF constructions in Yukatek and Lakandon Maya. There is furthermore no trace of a reflex of the reconstructed agent focus suffixes $*_{\text {-on }}$ or $*$-wa in Yukatek and Lakandon Maya. In examples (7-11), AF constructions are exemplified with data from Lakandon Maya: 
mahk (X-)kihn-s-ej-Ø

who die-CAUS-DEP.TR-3SG.B

'Who killed it?'

xiiraj raji7 (X-)kihn-s-ej-Ø

b'ahrum

man 3SG.IND die-CAUS-DEP.TR-3SG.B jaguar

'It was this man who killed the jaguar'

mana7-Ø mahk (X-)ir-ej- $\varnothing$

NEG.EXIST-3SG.B who see-DEP.TR-3SG.B

'No one saw him'

(10) mahk b'ihn (X-)kihn-s-ik- Ø

who FUT die-CAUS-PLN.TR-3SG.B

'Who is going to kill it?'
a-je7 xiiraj raji7
(X-)kihn-s-ik- $\varnothing$
b'ahrum
DET-OST man 3SG.IND die-CAUS-PLN.TR-3SG.B jaguar
'This man, it is he who kills jaguars'

In (7-9) the completive aspect is implied given the past reading of the examples although no explicit completive marker is present on the verb. All three examples are inflected with the dependent status marker. In (10) the future marker b'ihn is combined with the plain status marker $-i k$ and in (11) the incompletive/habitual reading is present along with the same status marker.

In (12), below, the changes in status marking between AF constructions and non-focused ones are displayed with data from Yukatek, which is almost identical to the Lakandon data with the exception of the optional $j+$ clitic that is unattested for Lakandon Maya AF constructions.

(12) Transitive status marking in "objective" and "agentive" constructions in Yukatek (after Kaufman 1991: 173).

\begin{tabular}{|l|l|l|}
\hline Aspect/Status markers & Objective voice & Agentive (AF) voice \\
\hline Completive & $-a j$ & $(j+\ldots-\ldots-e(j)$ \\
\hline Indefinite future & $-e(j)$ & $-i k$ \\
\hline Plain/Incompletive & $-i k$ & $(j+) \ldots-i k$ \\
\hline
\end{tabular}

The changes sketched in (12) are what the present paper proposes to explain from a syntactic and a semantic point of view. Kaufman reports that the changes are

\footnotetext{
${ }^{6}$ This was not the case in Colonial Yukatek where an agent focused verb phrase in the completive took an unidentified suffix $(-i)$. There has been a reanalysis in Modern Yukatek and Lakandon of this suffix to match the dependent status marker.
} 
unclear, but that the status suffixes could be explained by relating each of them to a proto-Mayan nominalization suffix. I will argue for a different explanation here.

Before moving on to these explanations it should be noted that AF constructions are not required when fronted by an agent pronoun form. The example in (11) should be contrasted to the one in (13), below:

$\begin{array}{lll}\boldsymbol{r a} \mathbf{a j i} 7 & \boldsymbol{k} \text { - } \boldsymbol{u} \text {-känah-t-ik-een} & \text { 7uhch } \\ \text { 3SG.IND } & \text { INC-3SG.A-guard-TRZ-PLN.TR-1SG.B } & \text { before.EXCL } \\ \text { 'He took care of me.' (HB050225_1KYYM_3) } & \end{array}$

The precise motivations for when AF constructions are used as opposed to when they are not remain to be investigated. From a cursory look at examples from my own corpus of analysed Lakandon Maya speech, it appears that AF verbs (unsurprisingly) are used in two contexts: 1) when the identity of the agent is in question, and 2) when the agent is emphasised for other reasons such as reminding the addressee of the identity of the agent.

\section{Grammatical Explanations for AF in Lakandon and Yukatek}

As stated at the outset of the paper, there are both syntactic and semantic motivations behind the grammatical changes mainly concerning status marking that are associated with AF in Yukatek and Lakandon Maya. I will start by discussing some syntactic features of these constructions and leave the semantics for section 6 since they need to be introduced by Lucy's analysis of verb roots in Yukatek in section 5, in order to make sense.

AF in Yukatek and Lakandon Maya results in a construction where the extracted, focused agent is followed by a dependent clause. Syntactically, the head of an AF construction maps onto free-standing AM-markers, such as $t z^{\prime} o 7 k$ and $7 u h c h$, which are analysed as heads, or one-place predicates that take the following verb phrase as an argument (cf. Bohnemeyer 1998). Bohnemeyer notes that focused- and relative phrases are identical in a morpho-syntactic sense, which means that an AF construction appears identical to a headless relative phrase.

There are two main pieces of evidence for why the verb phrase should be analysed as depending on the extracted agent in the form of an interrogative or personal pronoun, 1) the prefixed aspect marker $k$ - is absent in AF constructions. This would not have been the case if the verb functioned as an independent verb phrase, 2) The interrogative marker wa(h), which occupies the syntactic slot directly after the main predicate is placed after the focused pronoun form and not after the following verb phrase, as seen in (14):

$$
\begin{array}{lll}
\text { raji7 } & \text { wah } & (X \text {-)känah-t-ik- } \varnothing \\
\text { 3SG.IND } & \mathrm{Q} & \text { guard-TRZ-PLN.TR-3SG.B }
\end{array}
$$

'Is it he who takes care of her?' 
The only two available statuses in dependent/subordinate verb phrases are the plain- and the dependent status. The completive status cannot be used in a subordinate, i.e. "non-finite" construction. It is therefore not surprising that the completive status is unavailable for AF constructions when placed in the context of the analysis presented here.

The formal and semantic analysis of AM-marking by Bohnemeyer (1998) for Yukatek suggests that the plain and the dependent status have "unbounded" and "bounded" characters, respectively, something that may go some way in explaining why the "bounded" dependent status marker is assigned to completive AF constructions.

However, it does not explain why non-focused dependent constructions are marked with the unbounded plain status in AF constructions. This should not be expected if the unbounded-bounded distinction is to be maintained. Bohnemeyer observes that AM- and status marking "conflates" in AF constructions, but this is only an observation and it does not explain the changes from a syntactic viewpoint. Therefore, I now turn to a semantic analysis of the observed changes in status marking in Yukatek and Lakandon Maya.

\section{Argument Structure as an Inherent Feature of Lexical Stems}

John Lucy (1994) proposes a classification of verb stems in Yukatek according to their inherent argument structure. The presence of argument structure as a semantic feature in verb stems can be observed from the way those stems interact with case and aspect (i.e. person- and status marking in my terms).

Lucy argues, for Yukatek, that there is a large class of agent-patient salient stems (Kaufman 1991: root transitives), a smaller group of agent salient ones (Kaufman 1991: action verbal nouns, or avns and affect roots), and a still smaller group of patient salient stems (Kaufman 1991: root intransitives).

The way in which formal marking by derivational and inflectional affixes and phonological changes to the stem is applied, provides clues as to how they should be understood and classified from a language internal perspective.

Agent-patient salient stems (transitive roots) are inflected with an ergative marker (set A) to mark the agent, and an absolutive marker (set B) to mark the patient. As transitive stems, they require no additional marking to indicate their transitive status (example 3 repeated):

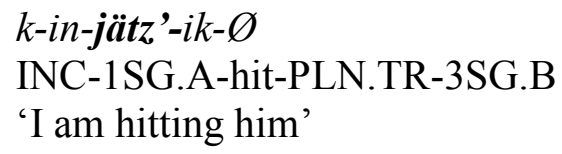

Agent salient stems are intransitive stems that denote an activity or an act involving an agent. They are made transitive using the $-t$ suffix (Lucy: affective) to indicate an increase in valence. 


\title{
Henrik Bergqvist
}

\author{
$k-u$-siht'-t-ik-Ø \\ INC-3SG.A-jump-TRZ-PLN.TR-3SG.B \\ 'He jumps (over) it'
}

Patient salient stems are oriented towards processes of becoming or of changing state. When they are derived to form a transitive construction, they take the causative $-s$ suffix, to indicate agency in making a patient change state.

k-uy-ehm-s-ik-Ø

INC-3SG.A-go.down-CAUS-PLN.TR-3SG.B

'He lowers it/He takes it down'

Valence increasing operations by 1 ) derivation (i.e. $-t$ and $-s$ ), 2) valence decreasing ones by phonological means, and 3) the presence/absence of inflected status markers are observed in order to discover unmarked forms of verb stems that are indicative of their natural state.

From observing these formal markings, Lucy proposes that the plain status (Lucy: imperfective) is agent salient; the dependent status (Lucy: gnomic perfective) is agent-patient salient; and the completive (Lucy: perfective) status is patient salient. The comparisons can be seen in (16), below:

$$
\text { Interaction of case and status in Yukatek }{ }^{7} \text { (after Lucy 1994:635) }
$$

\begin{tabular}{|c|c|c|c|}
\hline $\begin{array}{l}\text { Stem } \rightarrow \\
\text { Status } \downarrow\end{array}$ & Agent: siht' & Agent/Patient: $k u c h$ & Patient: $k i h m$ \\
\hline $\begin{array}{l}\text { Plain } \\
\text { Agent } \\
\text { Agent/Patient } \\
\text { Patient } \\
\end{array}$ & $\begin{array}{l}\text { in-siht' }=\mathbf{0}=\mathbf{0 - 0 - 0} \\
\text { in-kuuch }=0=\mathrm{L}-0-0 \\
\text { in-kihm }=\mathrm{s}=\text { aj-0-0 }\end{array}$ & $\begin{array}{l}\text { in-siht' }=t=0-0-i k-e c h \\
\text { in-kuch }=0=0-0 \text {-ik-ech } \\
\text { in-kihm }=s=0-0-i k-e c h\end{array}$ & $\begin{array}{l}\text { - } \\
\text { a-kuhch }=0=H-0 \text {-ul } \\
\text { a-kihm }=0=0-0-\mathrm{i} 1\end{array}$ \\
\hline $\begin{array}{l}\text { Dependent } \\
\text { Agent } \\
\text { Agent/Patient } \\
\text { Patient } \\
\end{array}$ & $\begin{array}{l}\text { siht' }=0=0 \text {-n-ak-en } \\
\text { kuuch }=0=\text { L-n-ak-en } \\
\text { kihm }=s=\text { aj-n-ak-en }\end{array}$ & $\begin{array}{l}\text { in-siht' }=t=0-0-0-\text { ech } \\
\text { in-kuch }=\mathbf{0}=\mathbf{0 - 0 - 0 - e c h} \\
\text { in-kihm }=s=0-0-0 \text {-ech }\end{array}$ & $\begin{array}{l}- \\
\text { kuhch }=0=H-0 \text {-uk-ech } \\
\text { kihm }=0=0-0 \text {-ik-ech }\end{array}$ \\
\hline $\begin{array}{l}\text { Completive } \\
\text { Agent } \\
\text { Agent/Patient } \\
\text { Patient }\end{array}$ & $\begin{array}{l}\text { siht' }=0=0 \text {-n-aj-en } \\
\text { kuuch }=0=\text { L-n-aj-en } \\
\text { kihm }=s=a j-n-a j-e n\end{array}$ & $\begin{array}{l}\text { in-siht' }=t=0-0 \text {-aj-ech } \\
\text { in-kuch }=0=0-0 \text {-aj-ech } \\
\text { in-kihm }=s=0-0 \text {-aj-ech }\end{array}$ & $\begin{array}{l}- \\
\text { kuhch }=0=\mathrm{H}-0-0-\mathrm{ech} \\
\mathbf{k i h m}=\mathbf{0}=\mathbf{0 - 0 - 0} \mathbf{- e c h}\end{array}$ \\
\hline
\end{tabular}

\footnotetext{
7 Derivation is marked by ' $=$ ', with $=0$ indicating the absence of overt morphology. Inflection is marked by '-': $-a j$ is an agentive suffix (i.e. anti-passive); $-n$ is the actual anti-passive suffix. $\mathrm{L}$ and $\mathrm{H}$ stand for low- and high tone respectively. Derivation by tone can justly be considered a derivational operation since the middle-passive and anti-passive constructions are both formed by such processes in both Yukatek and Lakandon. High tone is also present in some possessive constructions that, if unpossessed, lack a high tone.
} 
A mismatch between the inherent valence value of the root and the status marker requires overt morphological marking. When the status marking and argument value of the root match, on the other hand, there is no need for overt marking.

The forms in bold are thus unmarked in the sense that they lack any overt morphological derivation or inflection in their respective functions. They represent a match between the inherent semantic features of the verb stem and the status (non-) marking that it combines with.

Lucy divides Yukatek predicates (following Vendler 1957) into activities (agent salient), accomplishments (agent-patient salient), and state changes (patient salient). He argues that the strong formal link between these predicate types and their respective status marking warrants the proposal that argument structure is an inherent semantic feature of the roots themselves as well as to their status counterparts.

The following analysis in section 6 regarding the changes in status marking in AF constructions in Yukatek and Lakandon Maya follows directly from Lucy's proposal. In fact, it supports Lucy's analysis since the grammatically separate AF construction conforms identically to the semantic division that Lucy advocates for the classification of verb stems.

\section{Argument Structure Hierarchy in AF}

There is a three-way division of status marking in Yukatek that reflects agent salience by degrees ${ }^{8}$ :

Agent salience hierarchy in Yukatek and Lakandon.

\begin{tabular}{|l|l|l|}
\hline Status & Transitive status suffixes & Argument structure hierarchy \\
\hline Plain & $-i k$ & $(1)$ Agent \\
\hline Dependent & $-\varnothing /-e(j)$ & $(1-2)$ Agent-Patient \\
\hline Completive & $-a j$ & $(2)$ Patient \\
\hline
\end{tabular}

The table in (17) is included to illustrate the proposal that agent-patient semantics are present in status markers given their interaction with verb stems in Yukatek. The only addition lies in calling the division of status markers according to agent salience an "argument structure hierarchy".

The proposal that follows from this hierarchy is that speakers of Yukatek and Lakandon Maya "upgrade" the status suffix one step on the hierarchy in AF constructions to a status marker that more closely reflects the focus on, or the salience of the agent.

In the case of the completive, the next status marker on the hierarchy is the dependent status. Compare ( $\left.7^{\prime}\right)$ to the repeated (7):

\footnotetext{
${ }^{8}$ Salience refers to a specific grammatical feature that is relevant for the description of a lexeme or a morpheme.
} 
$-A J \rightarrow-E(J) /-\varnothing=2 \rightarrow 1-2$

(7') teen t-in-kihn-s-aj- $\varnothing$

1SG.IND COM-1SG.A-die-CAUS-DEP.TR-3SG.B

'I killed him'

(7) mahk (X-)kihn-s-ej-Ø

who die-CAUS-DEP.TR-3SG.B

'Who killed him?'

If the verb is inflected with the dependent status, the next step is the plain status. Compare the $\left(10^{\prime}\right)$ to the also repeated (10):

$-E(J) \rightarrow-I K=1-2 \rightarrow 1$

(10') b'ihn in-kihn-s-ej-Ø

FUT 1SG.A-die-CAUS-DEP.TR-3SG.B

'I am going to kill him'

(10) mahk b'ihn (X-)kihn-s-ik-Ø

who FUT die-CAUS-PLN.TR-3SG.B

'Who is going to kill it/him?'

Finally, when the status is already agent salient, no additional marking or change occurs and the agent focus construction in the plain status simply stays the same. Compare (13) with (11), both repeated here:

$-I K \rightarrow-I K=1 \rightarrow 1$

ra7ji7 k-u-känah-t-ik-een

7 uhch

3SG.IND INC-3SG.A-guard-TRZ-PLN.TR-1SG.B before.EXCL

'He took care of me.' (HB050225_1KYYM_3)

$$
\text { a-je7 xiiraj raji7 (X-)kihn-s-ik-Ø b'ahrum }
$$

DET-OST man 3SG.IND die-CAUS-PLN.TR-3SG.B jaguar

'This man, he kills jaguars'

\section{Summary}

The presence of inherent argument structure as a semantic feature of status markers as well as verb stems in Yukatek and Lakandon Maya gives us a possible answer to the questions, why and how the status markers change in AF constructions in Yukatek and Lakandon Maya.

Having pointed out differences between AF constructions in Yukatek and Lakandon Maya and other Mayan languages such as Tzotzil, the syntactic analysis of AF constructions was considered as partly determining the observed changes that occur in AF constructions in the former languages. 
Since some of the changes are insufficiently explained by the syntactic analysis alone, a hierarchy of agent salience is proposed as a semantic way of explaining AF constructions involving ergative extraction. The AF construct in Yukatek and Lakandon Maya in turn offer support for the analysis proposed by Lucy (1994) regarding the classification of verb stems and their interaction with case markers.

It is impossible on both syntactic and semantic grounds for the completive status marker to be present in AF constructions because of its status as a marker of independent (finite) phrases as well as from its patient-salient semantics.

The future AM-marker, b'ihn, groups together with the plain status, -ik, not because of any grammatical requirements, but for semantic reasons, which are considered in the proposed hierarchy in section 6.

The pragmatic motivations underlying the use of AF constructions in Yukatek and Lakandon, as opposed to non-focussed ones, remain to be investigated.

\section{References}

Aissen, Judith. 1997. On the Syntax of Obviation. Language 73(4):705-750.

Aissen, Judith. 1999. Agent Focus and Inverse in Tzotzil. Language 75(3):451-485.

Bohnemeyer, Jürgen. 1998. Time Relations in Discourse: Evidence from a comparative Approach to Yucatec Maya. Ph.D. diss., Katholieke Universiteit.

Bohnemeyer, Jürgen. 2004. Split Intransitivity, linking and lexical representation: the case of Yukatek Maya. Linguistics 42:67-107.

Dayley, Jon P. 1985. Tz'utujil grammar. Berkeley: University of California Press.

Dixon, R. M. W. 1972. The Dyirbal Language of North Queensland. Cambridge: Cambridge University Press.

Lucy, John. 1994. The role of semantic value in lexical comparison: motion and position roots in Yucatec Maya. Linguistics 32:623-656.

Kaufman, Terrence. 1990. Algunos Rasgos Estructurales de los Idiomas Mayances con Referencia Especial al K'iche'. In England, Nora C., Elliot Stephen R. (eds.). Lecturas sobre la Linguistica Maya, 59-116, Plumsock Mesoamerican Studies, Vermont.

Kaufman, Terrence. 1991. Notes on the Structure of Yukateko and other Yukatekan languages (Nov-Dec 1991). PDLMA handout, 106-210.

Vendler, Zeno. 1957. Verbs and Times. Philosophical Review 66:143-160.

Yasugi, Yoshiho. 2005. Fronting of Nondirect Arguments and Adverbial Focus Marking on the Verb in Classical Yucatec. IJAL 71(1):56-86. Chicago: The University of Chicago.

Henrik Bergqvist

Folkskolegatan 4

11735 Stockholm

Sweden

four.mount@swipnet.se 